Jawad F. Kirmani, MD

Ammar Alkawi, MD

Spozhmy Panezai, MD

Martin Gizzi, MD, PhD

Correspondence \& reprin

requests to Dr. Kirmani:

jkirmani@gmail.com

\title{
Advances in thrombolytics for treatment of acute ischemic stroke
}

\section{ABSTRACT}

Over the past 50 years, thrombolytic agents have been devised with the aim of recanalizing occluded coronary vessels, and later on, applied in the setting of acute ischemic stroke. Pharmacologic agents have generally targeted the plasminogen-plasmin transformation, facilitating the natural process of fibrinolysis. Newer agents with varying degrees of fibrin selectivity and pharmacologic half-life have influenced both recanalization rates and hemorrhagic complications, inside and outside the CNS. Intra-arterial (IA) administration of fibrinolytic agents increases delivery of the drug to the thrombus at a higher concentration with smaller quantities and therefore lowers systemic exposure. Mechanical thrombus disruption or extraction allows for drug delivery to a greater surface area of the thrombus. Delays associated with IA therapy may worsen the risk/ benefit ratio of thrombolysis; therefore, combinations of IA-IV treatments have been studied. To date, there are no direct comparative trials to show that endovascular administration is more efficacious or carries a lower risk of hemorrhagic complications than IV tissue plasminogen activator. Neurology ${ }^{\circledR}$ 2012;79 (Suppl 1):S119-S125

\section{GLOSSARY}

AIS = acute ischemic stroke; DIAS = Desmoteplase in Acute Ischemic Stroke Trial; ECASS = European Cooperative Acute Stroke Studies; FDA = US Food and Drug Administration; IA = intra-arterial; ICH = intracerebral hemorrhage; $\mathbf{M C A}=$ middle cerebral artery; MMPs = matrix metalloproteinases; MRA = magnetic resonance angiography; NIHSS = NIH Stroke Scale; NINDS = National Institute of Neurological Disorders and Stroke; PROACT = Prolyse in Acute Cerebral Thromboembolism; rtPA = recombinant tissue plasminogen activator; TIMI = thrombolysis in myocardial ischemia; tPA = tissue plasminogen activator

Stroke is the fourth leading cause of death in the United States and is a major cause of disability worldwide. ${ }^{1-3}$ Over the past 20 years, many advances in the treatment of stroke have been directed at better prevention and acute intervention in an effort to improve clinical outcomes and decrease associated mortality. Most of the acute interventions target the salvageable ischemic penumbra. This is best achieved by IV or intra-arterial (IA) thrombolysis. Ongoing development of thrombolytic agents has produced 4 generations of drugs based on fibrin specificity and pharmacologic half-life. In addition, interventional mechanical devices can enhance the performance of thrombolytic agents.

THROMBOLYTICS Vessel occlusion, caused by a blood clot, interrupts cerebral blood flow and results in an acute ischemic stroke (AIS). Most commonly, the clot comprises a mesh of fibrin and platelets. The resultant cerebral infarct has a core lesion containing dead tissue and a surrounding viable ischemic penumbra. The ischemic penumbra is a region of hypoperfused and dysfunctional cerebral tissue, which may be salvageable. The stability and size of the penumbra are dependent mainly on the collateral blood supply. ${ }^{4}$ Rapid restoration of blood flow through dissolution of the obstructing clot allows recovery of the penumbra.

Thrombolytic agents aim at disrupting the fibrin-rich clot that is created in response to injury of the endothelium. ${ }^{5}$ By activating plasminogen, the administration of thrombolytics leads to an increased production of plasmin, which dissolves the fibrin bonds in the clot (figure 1). When IV thrombolysis occurs, rapid local and systemic complications may be minimized. However, this time constraint is one of the major limitations of thrombolytic use, and penumbral imaging becomes of paramount significance in triaging AIS

From the New Jersey Neurological Institute, JFK Neuroscience Institute, Edison.

Go to Neurology.org for full disclosures. Disclosures deemed relevant by the authors, if any, are provided at the end of this article. 
Figure 1 The specificity for bound plasmin increases and systemic effects decrease as thrombolytics progress from first generation to fourth

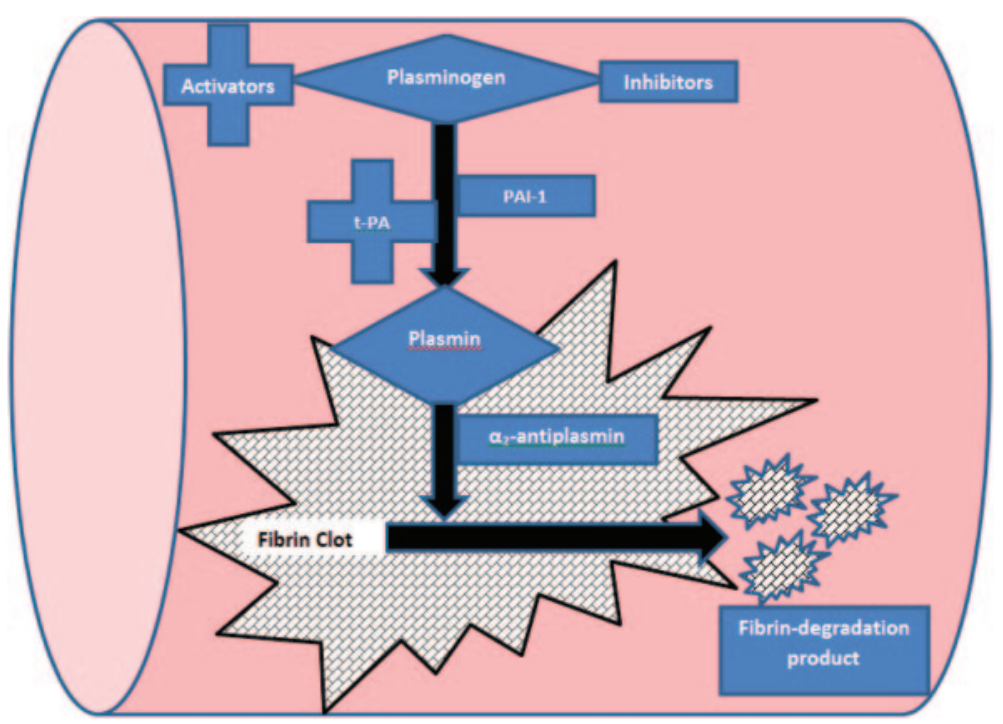

First, streptokinase and urokinase; second, alteplase and prourokinase; third/fourth, reteplase, tenecteplase, monteplase, desmoteplase, and lanoteplase (t-PA = tissue plasminogen activator; $\mathrm{PAI}-1$ = plasminogen activator inhibitor 1 ).

patients for thrombolytic therapy, which is addressed elsewhere in the supplement.

First generation. Streptokinase and urokinase are the first generation of thrombolytics. Although they are effective in clot lysis, they are not fibrin-specific.

Streptokinase is the oldest thrombolytic agent. It is naturally produced by bacteria and was isolated and manufactured in the 1950 s. ${ }^{6}$ Streptokinase is known to have immunogenic properties that may reduce its effectiveness or induce an allergic reaction. Early trials of streptokinase as a treatment for AIS had poor outcomes and were all terminated early because of increased mortality related to the development of intracerebral hemorrhage (ICH) after treatment. ${ }^{8}$ During these early trials, investigators were unable to recruit patients within the first few hours of symptom onset, and many patients were enrolled days later. This delay, among other factors, contributed to the increased incidence of hemorrhages. ${ }^{8}$

More trials using streptokinase were conducted in the late 1980s and early 1990s. These included the Australian Streptokinase Trial (AST), the Multicenter Acute Stroke Trial (MAST), and the Multicenter Acute Stroke Trial in Italy (MAST-I). ${ }^{7,9}$ In these trials, IV streptokinase was administered within 4 to 6 hours of symptom onset. The results failed to show clear benefit and led to abandonment of its use in the treatment of AIS.

Urokinase was developed and studied in the 1970s. In the early 1980s, 3 trials tested IV urokinase in AIS. Again, these trials recruited patients up to several days after stroke onset and, as a result, had high rates of ICH. In 1980, the NIH consensus recommended that thrombolysis of acute cerebrovascular disorders be contraindicated, ${ }^{10}$ thus limiting its use in treatment of AIS.

Second generation. Alteplase is a protease that is thought to exert a neurotoxic effect on the brain parenchyma when it crosses the blood-brain barrier. It also amplifies calcium currents through the NMDA receptor leading to neuroexcitotoxicity and cell death. ${ }^{11,12}$ Alteplase directly activates matrix metalloproteinases (MMPs), which have been found to play a role in blood-brain barrier breakdown and neuronal injury in a stroke. Because these proteases may increase the risk of ICH and cerebral edema, early administration of the drug prior to natural MMP activation is ideal.

The second-generation thrombolytics include recombinant tissue plasminogen activator (rtPA), also known as alteplase, and prourokinase. These agents are more fibrin-selective and have been studied extensively in ischemic stroke. ${ }^{13-16}$ The National Institute of Neurological Disorders and Stroke (NINDS) tissue plasminogen activator ( $\mathrm{tPA}$ ) trial was the first study to demonstrate efficacy of alteplase in patients with AIS. The efficacy was based on administering tPA, $0.9 \mathrm{mg} / \mathrm{kg} \mathrm{IV}$, given within 3 hours of symptom onset. ${ }^{16}$ On the basis of the results of this study, the US Food and Drug Administration (FDA) approved IV alteplase for treatment of AIS. Patients who received treatment within the first 90 minutes had a more favorable outcome at 3 months than patients who were treated after 90 minutes. ${ }^{17}$

The European Cooperative Acute Stroke Studies (ECASS I, II, and II) looked at the efficacy of IV alteplase within 6 hours of symptom onset. These studies did not show significant improvement in neurologic outcomes at 3 months in comparison with placebo. ECASS I used a dose of $1.1 \mathrm{mg} / \mathrm{kg}$, a higher dose than the NINDS rtPA study, which led to a higher incidence of ICH (19.8\%). ${ }^{13}$ A lower dose of $0.9 \mathrm{mg} / \mathrm{kg}$ was used in ECASS II, and a lower $\mathrm{ICH}$ rate $(8 \%)$ was observed, as well as a trend toward better outcome. ${ }^{14}$ The ATLANTIS study began as an investigation of alteplase used within 6 hours of symptom onset. Because of safety concerns, the time window was shortened to 5 hours. ${ }^{15}$ A pooled analysis of the ATLANTIS, ECASS, and NINDS trials showed beneficial effects of IV alteplase up to 4.5 hours after symptom onset. There was no significant benefit when it was given between 4.5 to 6 hours. ${ }^{18}$ ECASS III showed that although overall symptomatic ICH was higher in treated patients, the rate was not higher in patients treated within the approved 3-hour window and was not associated with in- 
creased mortality. The results were significant across multiple endpoints and showed efficacy of treatment despite an increased rate of hemorrhage within 3 to 4.5 hours of symptom onset. ${ }^{19}$ There is evidence from MRI protocols and several studies that IV thrombolysis beyond 3 hours in selected patients can be effective..$^{20,21}$

Prourokinase is a proenzyme precursor of urokinase. When activated by fibrin-associated plasmin, 2 single-chain prourokinase units bind at the surface of the thrombus to form an active 2-chain urokinase molecule. ${ }^{22}$ The thrombolytic effect is enhanced by heparin, possibly through neutralization of thrombin or by stimulating tPA from the endothelium. ${ }^{23,24}$ Prourokinase was utilized for IA thrombolysis studies in the mid-1990s. The Prolyse in Acute Cerebral Thromboembolism (PROACT) trial evaluated IA infusion of prourokinase $(6 \mathrm{mg})$ vs placebo for treatment of middle cerebral artery (MCA) occlusion in patients who presented within 6 hours of symptom onset. ${ }^{25}$ At 90 days, there was a $10 \%$ to $12 \%$ absolute increase in excellent neurologic outcome, defined as a modified Rankin Scale score of 2 or less, in the patients who received prourokinase compared with placebo. Symptomatic hemorrhages within the first 24 hours occurred in $15.4 \%$ of patients who received prourokinase, vs $7.1 \%$ in the placebo group. The PROACT II trial compared patients who received an IA infusion of prourokinase $(9 \mathrm{mg}$ ) and low-dose heparin vs low-dose heparin alone within 6 hours of symptom onset for treatment of angiographically proven MCA occlusion. ${ }^{26}$ Although early symptomatic hemorrhage occurred in $10 \%$ of the IA prourokinase group vs $2 \%$ in the control group, there was a $15 \%$ absolute increase in favorable outcome with IA prourokinase. However, despite these results, prourokinase did not gain FDA approval for use in AIS.

Although these second-generation agents may be beneficial, there are still a significant number of patients who did not respond to treatment, had low recanalization rates, or had high rates of reocclusion. ${ }^{5}$ In addition, hemorrhagic complications occurred frequently when these agents were used. Due to the potentially poor clinical outcome, the need for newer thrombolytic agents with lower adverse profiles and possibly longer therapeutic windows remained.

Third/fourth generation. Several third- and fourthgeneration thrombolytics are being developed, including mutants of scuPA and tPA; chimeric plasminogen activators of these 2 molecules (amediplase); conjugates of plasminogen activators with monoclonal antibodies against fibrin, platelets, or thrombomodulin; and plasminogen activators of animal (vampire bat) or bacterial (Staphylococcus aureus) origin. $^{27}$ These agents have longer half-lives in plasma, allowing for single or repeated bolus injections, as opposed to the continuous infusion required with the first- and second-generation thrombolytics. They have higher fibrin specificity and lower or no neurotoxicity, which may in turn lead to lower hemorrhagic complications. ${ }^{5,12}$

Staphylokinase is a highly fibrin-selective agent. It has a low affinity for plasminogen that is free or bound to intact fibrin, but it binds strongly to plasmin and to plasminogen that is bound to partially degraded fibrin. ${ }^{28}$ This feature enables it to concentrate on the surface of a lysing thrombus. The staphylokinase-plasmin complex is rapidly inhibited by $\alpha_{2}$-antiplasmin in the absence of circulating fibrin. When bound to fibrin, the complex is protected from inhibition. Thus, staphylokinase acts as an indirect activator of plasminogen within a thrombus. ${ }^{12,28}$ Nevertheless, this agent has not been extensively studied for use in AIS.

Tenecteplase is another third-generation agent that is more fibrin-specific than alteplase and may reduce the risk of systemic complications. ${ }^{29,30}$ It has a longer half-life (15 to 19 minutes) and greater resistance to plasminogen-activator inhibitor. ${ }^{5}$ The "plasminogen steal" effect that is seen with alteplase is not seen with tenecteplase, thus making it more effective. ${ }^{30}$ This phenomenon occurs when high levels of alteplase lower systemic plasminogen levels, which leads to a paradoxical diffusion of plasminogen out of the clot, thereby reducing clot lysis. ${ }^{12,31}$

Tenecteplase has been tested in AIS patients in phase II trials. ${ }^{32,33}$ At this point, the most beneficial dose of tenecteplase is unclear. A small pilot study using magnetic resonance angiography (MRA) and MRI perfusion-weighted imaging showed improved recanalization and reperfusion rates in 15 patients receiving $0.1 \mathrm{mg} / \mathrm{kg}$ tenecteplase and 35 patients receiving standard doses of tPA. ${ }^{32}$ There were no cerebral hemorrhages in the tenecteplase group, but 4 were seen in the tPA group. A recent phase IIB/III trial comparing $0.1 \mathrm{mg} / \mathrm{kg}, 0.25 \mathrm{mg} / \mathrm{kg}$, and 0.4 $\mathrm{mg} / \mathrm{kg}$ tenecteplase with $\mathrm{tPA}$ was ended prematurely because of poor enrollment. ${ }^{34}$ A total of 112 patients were randomized, and the $0.4-\mathrm{mg} / \mathrm{kg}$ dose was discarded early because of inferiority and a higher rate of ICH. Optimal dose selection could not be made between the $0.1 \mathrm{mg} / \mathrm{kg}$ and $0.25 \mathrm{mg} / \mathrm{kg}$ doses because of the termination of the study. ${ }^{34}$

Reteplase is a deletion mutant of $\mathrm{tPA}^{5}$ that lacks the terminal domains of alteplase, including the terminal finger, epidermal growth factor, and kringle 1 domains. ${ }^{27}$ As a result, reteplase does not bind strongly to fibrin, allowing unbound reteplase to penetrate the thrombus and promote lysis. It has a reduced affinity for binding to endothelial cells and 
monocytes, which in turn leads to higher levels in the bloodstream. Reteplase has a longer half-life (15 to 18 minutes) than alteplase and may be given as a bolus. ${ }^{5}$ It is used for IA thrombolysis in AIS. The first human clinical trial using this agent intra-arterially was reported in 2001. ${ }^{35}$ Sixteen patients who were poor candidates for IV alteplase were selected for therapy. Selection criteria included a time interval of 3 hours or longer from symptom onset or severe neurologic deficit on presentation (NIH Stroke Scale [NIHSS] scores ranged from 10 to 26). This was primarily a dose escalation safety trial. Of the 16 treated patients, 1 had symptomatic ICH. A modified thrombolysis in myocardial infarction (TIMI) grading system was used, and the authors reported TIMI 3 or 4 (equivalent to the original TIMI grade 3) recanalization rates in $88 \%$ of patients. This high rate of recanalization was achieved even though 8 of $16 \mathrm{pa}$ tients presented with occlusion of either the cervical $(n=4)$ or intracranial $(n=4)$ internal carotid artery. Forty-four percent of patients had early neurologic improvement (defined as a decrease of 4 or more points in the NIHSS score at 24 hours). However, further studies are necessary to evaluate the proper dosage and durability of reteplase for IA thrombolysis in AIS.

Desmoteplase is a serine protease that naturally occurs in the saliva of the bat Desmodus rotundus. ${ }^{12} \mathrm{It}$ has pharmacologic and toxicologic properties superior to human $\mathrm{tPA}$, including a higher fibrin selectivity, lower hemorrhagic transformation profile, longer half-life, and lack of NMDA-mediated neurotoxicity, in comparison with alteplase. ${ }^{12,35,36}$ The Desmoteplase in Acute Ischemic Stroke Trial (DIAS) was an MRI-based phase II study. DIAS was conducted to explore the safety and efficacy of various

\section{Figure 2 An example of intra-arterial treatment only: a 42-year-old man with sudden onset of global aphasia and right-sided hemiplegia peri- cardiac catheterization presenting within 2 hours of symptoms to the neuro-angio suite}

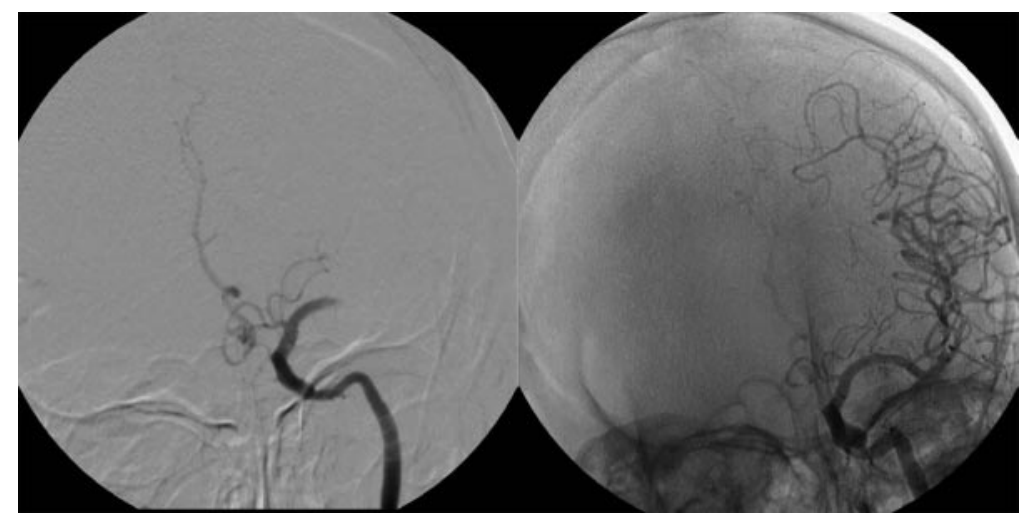

The left internal carotid injection demonstrated complete occlusion of the middle cerebral artery $\mathrm{M} 1$ segment (thrombolysis in cerebral ischemia score [TICI] 0), treated with intra-arterial recombinant tissue plasminogen activator for a total of $22 \mathrm{mg}$, with complete recanalization ( $\mathrm{TICl} 3$ ) and near-complete clinical improvement to an NIH Stroke Scale score of 2. doses of IV desmoteplase in patients with AIS and evidence of perfusion/diffusion mismatch with symptom onset between 3 and 9 hours. ${ }^{37}$ Results showed a higher rate of reperfusion $(71.4 \%)$ and a favorable 90 -day clinical outcome $(60.0 \%)$ compared to placebo (19.2\% and $22.2 \%$, respectively), and a low rate of symptomatic intracranial hemorrhage using doses up to $125 \mu \mathrm{g} / \mathrm{kg} .{ }^{37}$ The phase III DIAS-2 study failed to show the same benefits. This was believed to be related to the inclusion of a large number of patients with mild strokes at baseline and no vessel occlusion, as well as a high response rate among placebo-treated patients. ${ }^{38}$ However, post hoc analysis showed a positive response in patients who had a proximal cerebral vessel occlusion or highgrade stenosis on baseline angiography. ${ }^{39}$ DIAS-3 and DIAS-4 phase III trials are currently underway to evaluate patients with AIS related to occlusion or high-grade stenosis of proximal arteries, as assessed by MRA or CT angiogram. ${ }^{40}$

Ancrod is a biological agent extracted from the venom of the Malayan pit viper that reduces blood fibrinogen levels. ${ }^{41}$ It induces defibrinogenation in humans by cleaving fibrinopeptide A from fibrinogen, thus depleting the substrate needed for thrombus formation. This substrate depletion indirectly

\section{Figure 3 Surface area for clot penetration may be increased with use of mechanical devices for thrombolysis to be more effective}

\section{Mechanical thrombolysis}
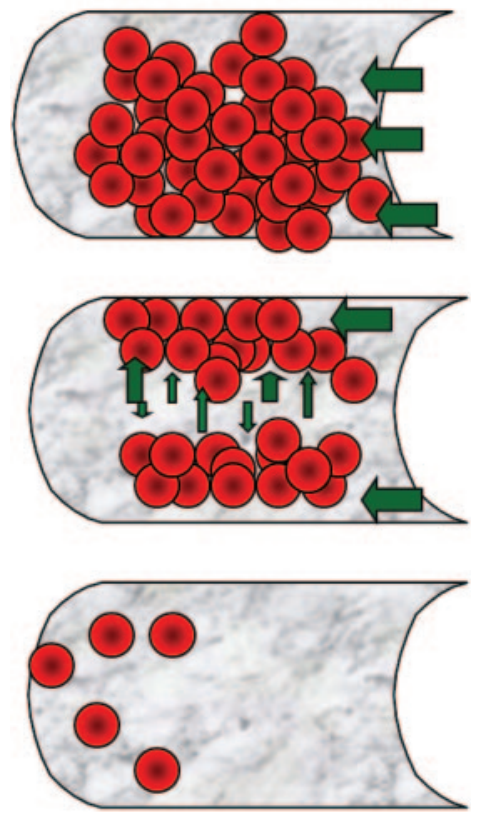

The middle illustration depicts a disrupted clot with a greater surface area. A longer half-life may further enhance clot lysis, as is the case with newer-generation thrombolytics. 
leads to anticoagulation and decreased blood viscosity, which later helps with improving circulation to affected areas. ${ }^{12,42-45}$ Products of defibrinogenation may also enhance local clot-specific thrombolysis by stimulating endogenous plasminogen activators. ${ }^{46}$ Two small trials of ancrod for AIS in the 1980s suggested that it was safe and beneficial in stroke patients. ${ }^{47,48}$ On the basis of these promising results, the Stroke Treatment with Ancrod Trial (STAT) was conducted. ${ }^{44}$ In this study, 500 patients who presented within 3 hours of symptom onset were randomized to receive ancrod or placebo as a continuous infusion over 72 hours and 1-hour infusions at 96 and 120 hours. Patients in the ancrod group had a more favorable functional outcome $(42.2 \%)$ than the placebo group (34.4\%) $(p=0.04)$. There appeared to be more symptomatic intracranial hemorrhages in the ancrod group (5.2\%) vs placebo recipients $(2.0 \%)(p=0.06)$, but the difference was not statistically significant. A follow-up clinical trial, in which 500 subjects with AIS were randomized within 6 hours of symptoms to ancrod at $0.167 \mathrm{IU} / \mathrm{kg}$ IV per hour vs placebo for 2 to 3 hours, showed no difference in clinical outcome between the 2 groups. ${ }^{49} \mathrm{~A}$ favorable functional outcome at $39.6 \%$ in the treatment arm vs $37.2 \%(p=0.47)$ was found. ${ }^{49}$

Intra-arterial delivery. Despite the improvement in functional outcome in stroke patients who receive IV rtPA, a large number of patients ( $57 \%$ to $58 \%$ ) die or become dependent despite treatment. ${ }^{13,16,50,51}$ This has prompted a search for better drugs and modalities of delivery that will achieve higher and quicker rates of recanalization with minimal risk to the pa-

\section{Figure 4 Histogram summary of the clinical outcome in the pivotal chemical thrombolysis IA trial, in comparison with the IV tissue plasminogen activator and control groups}

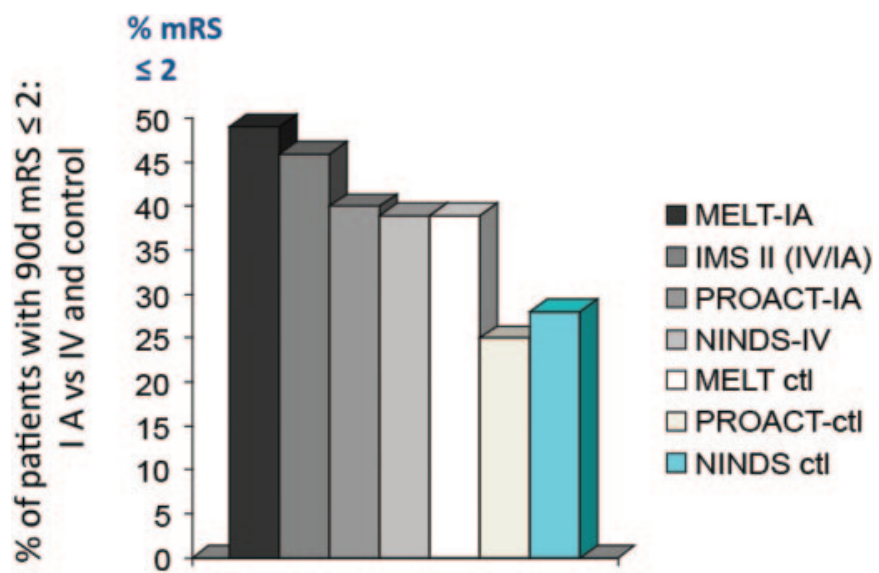

$\mathrm{Ct} \mid$ = control; IA = intra-arterial; IMS = Interventional Management of Stroke; MELT = Middle cerebral artery Embolism Local fibrinolytic intervention Trial; $m R S=$ modified Rankin Scale score; NINDS = National Institute of Neurological Disorders and Stroke; PRO$\mathrm{ACT}=$ Prolyse in Acute Cerebral Thromboembolism. tient. IA thrombolysis involves administration of high concentrations of thrombolytic agents near the thrombus, utilizing lower doses than systemic administration. This may result in lower systemic complications, including extracranial hemorrhages (figure 2), and minimizing local neurotoxic effects of these agents. ${ }^{5}$ This approach also allows the simultaneous use of mechanical devices to facilitate thrombolysis (figure 3).5,52,53 Combining the IA delivery with mechanical thrombectomy increases the surface area exposed to the thrombolytic agents (figure 2). The disadvantages of the IA modality include the potential delay required to obtain initial cerebral angiography and position of the microcatheter for administration of the thrombolytic agent. These concerns led to the initiative of delivering the IA thrombolysis following IV thrombolysis. The Emergency Management of Stroke (EMS) bridging trial, which had a randomized, double-blind, placebocontrol design, demonstrated higher recanalization rates $(53 \%)$ in the combined IV/IA alteplase treatment group than in the IA alteplase group (28\%). ${ }^{54}$ There was no difference in clinical outcomes between the 2 groups and no significant difference in the rate of symptomatic ICH. This suggested the feasibility of the combined treatment. Although in some centers the IA approach is favored in a subset of patients who are expected to have limited response to IV treatment, including those with severe neurologic deficits, those presenting between 3 and 6 hours of symptom onset, those who have a history of major surgery within the previous 2 weeks, and those with occlusion of major cervical or intracranial vessels, this has yet to be proven in controlled trials. ${ }^{51}$

Another combined approach involves using IA treatment initially to maximize the rate of recanalization, followed by IV infusion to increase the efficacy of the treatment. ${ }^{55}$ This approach was studied but the results were inconclusive. ${ }^{12}$

Thrombolytics are also known to activate thrombin, which promotes platelet adhesion and potentially reocclusion of patent vessels. ${ }^{56}$ No conclusive data on combining the IA thrombolysis delivery with a glycoprotein IIb/IIIa platelet receptor inhibitor via an IA or IV route exist. However, a glycoprotein IIb/ IIIa receptor inhibitor, abciximab, was evaluated for safety and efficacy in AIS. The Abciximab in Ischemic Stroke pilot study was a randomized, doubleblind, placebo-controlled, dose-escalation trial, where 4 escalated doses of IV abciximab were administered up to 24 hours after stroke onset. ${ }^{57}$ It showed a relatively low risk of $\mathrm{ICH}(7 \%)$ and a trend toward improved outcome after 30 days. It was concluded that abciximab was safe to use within 24 hours after stroke onset. However, the trial failed to 
demonstrate safety or efficacy of IV abciximab; in fact, there was an increased rate of symptomatic or fatal hemorrhage. ${ }^{58}$

DISCUSSION IA fibrinolysis is an effective AIS therapy within 6 hours of symptom onset, in comparison with placebo. A meta-analysis of IA thrombolysis studies showed that this approach substantially increases recanalization rates and good clinical outcomes in AIS. ${ }^{59} \mathrm{~A}$ higher rate of ICH was not associated with any increase in mortality (figure 4)..$^{59}$

Future directions. The best way of delivering IA fibrinolysis-alone, in combination with mechanical thrombectomy, as systemic thrombolysis, or followed by antiplatelet therapy-remains to be determined after further study.

The development of newer-generation thrombolytic agents, safer and more effective for treating AIS, is needed. This may be accomplished by increased fibrin specificity, rapid onset of action, and shorter half-life to improve on safety.

\section{AUTHOR CONTRIBUTIONS}

Dr. Kirmani: study concept or design, study supervision. Dr. Alkawi: drafting/revising the manuscript, study concept or design, analysis or in terpretation of data, acquisition of data, study supervision. Dr. Panezai: drafting/revising the manuscript. Dr. Gizzi: drafting/ revising the manuscript, study supervision.

\section{DISCLOSURE}

Dr. Kirmani has served on the Editorial Board of Frontiers in Endovascular and Interventional Neurology. Dr. Alkawi, Dr. Panezai, and Dr. Gizzi report no disclosures. Go to Neurology.org for full disclosures.

Received July 9, 2011. Accepted in final form February 23, 2012.

\section{REFERENCES}

1. National Center for Health Statistics. Deaths: leading causes (data for US in 2009). Available at: http://www.cdc. gov/nchs/fastats/lcod.htm.

2. Kalache A, Aboderin I. Stroke: the global burden. Health Policy Plan 1995;10:1-21.

3. Murray CJ, Lopez AD. Global mortality, disability, and the contribution of risk factors: Global Burden of Disease Study. Lancet 1997;349:1436-1442.

4. Liebeskind DS. Reperfusion for acute ischemic stroke: arterial revascularization and collateral therapeutics. Curr Opin Neurol 2010;23:36-45.

5. Qureshi AI, Pande RU, Kim SH, Hanel RA, Kirmani JF, Yahia AM. Third generation thrombolytics for the treatment of ischemic stroke. Curr Opin Investig Drugs 2002; 3:1729-1732.

6. Zivin JA. Thrombolytic stroke therapy: past, present, and future. Neurology 1999;53:14-19.

7. Cornu C, Boutitie F, Candelise L, et al. Streptokinase in acute ischemic stroke: an individual patient data metanalysis. Stroke 2000;31:1555-1560.

8. MAST-I Trial Investigators. Randomised controlled trial of streptokinase, aspirin, and combination of both in treatment of acute ischaemic stroke: Multicentre Acute Stroke TrialItaly (MAST-I) Group. Lancet 1995;346:1509-1514.
9. Donnan GA, Hommel M, Davis SM, McNeil JJ. Streptokinase in acute ischaemic stroke: Steering Committees of the ASK and MAST-E trials: Australian Streptokinase Trial. Lancet 1995;346:56.

10. Thrombolytic therapy in thrombosis: a National Institutes of Health consensus development conference. Ann Intern Med 1980;93:141-144.

11. Kaur J, Zhao Z, Klein GM, Lo EH, Buchan AM. The neurotoxicity of tissue plasminogen activator? J Cereb Blood Flow Metab 2004;24:945-963.

12. Donnan GA, Howells DW, Markus R, Toni D, Davis SM. Can the time window for administration of thrombolytics in stroke be increased? CNS Drugs 2003;17:995-1011.

13. Hacke W, Kaste M, Fieschi C, et al. Intravenous thrombolysis with recombinant tissue plasminogen activator for acute hemispheric stroke: The European Cooperative Acute Stroke Study (ECASS) [see comment]. JAMA 1995;274:10171025.

14. Hacke W, Kaste M, Fieschi C, et al. Randomised doubleblind placebo-controlled trial of thrombolytic therapy with intravenous alteplase in acute ischaemic stroke (ECASS II): Second European-Australasian Acute Stroke Study Investigators [see comment]. Lancet 1998;352:1245-1251.

15. Clark WM, Wissman S, Albers GW, Jhamandas JH, Madden KP, Hamilton S. Recombinant tissue-type plasminogen activator (alteplase) for ischemic stroke 3 to 5 hours after symptom onset: the ATLANTIS study: a randomized controlled trial: Alteplase Thrombolysis for Acute Noninterventional Therapy in Ischemic Stroke [see comment]. JAMA 1999;282:2019-2026.

16. The National Institute of Neurological Disorders and Stroke rt-PA Stroke Study Group. Tissue plasminogen activator for acute ischemic stroke. N Engl J Med 1995;333:1581-1587.

17. Marler JR, Tilley BC, Lu M, et al. Early stroke treatment associated with better outcome: the NINDS rt-PA Stroke Study. Neurology 2000;55:1649-1655.

18. Hacke W, Donnan G, Fieschi C, et al. Association of outcome with early stroke treatment: pooled analysis of ATLANTIS, ECASS, and NINDS rt-PA. Lancet 2004; 363:768-774.

19. Hacke W, Kaste M, Bluhmki E, et al., for ECASS III Investigators. Thrombolysis with alteplase 3 to 4.5 hours after acute ischemic stroke. N Engl J Med 2008;359:1317-1329.

20. Schellinger PD, Kaste M, Hacke W. An update on thrombolytic therapy for acute stroke. Curr Opin Neurol 2004; 17:69-77.

21. The Internet Stroke Center, Stroke Trials Directory. Available at: http://www.strokecenter.org/trials/TrialDetail.asp? ref $=475 \&$ browse $=$ search. Accessed December 28, 2009.

22. Pannell R, Gurewich V. Pro-urokinase: a study of its stability in plasma and of a mechanism for its selective fibrinolytic effect. Blood 1986;67:1215-1223.

23. Tebbe U, Windeler J, Boesl I, et al. Thrombolysis with recombinant unglycosylated single-chain urokinase-type plasminogen activator (saruplase) in acute myocardial infarction: influence of heparin on early patency rate (LIMITS study): Liquemin in Myocardial Infarction During Thrombolysis With Saruplase. J Am Coll Cardiol 1995;26:365-373.

24. Gurewich V, Liu JN. Intra-arterial pro-urokinase in ischemic stroke. Stroke 1998;29:1255-1256.

25. del Zoppo GJ, Higashida RT, Furlan AJ, Pessin MS, Rowley HA, Gent M. PROACT: a phase II randomized trial of recombinant pro-urokinase by direct arterial delivery in 
acute middle cerebral artery stroke: PROACT Investigators: Prolyse in Acute Cerebral Thromboembolism [see comment]. Stroke 1998;29:4-11.

26. Furlan A, Higashida R, Wechsler L, et al. Intra-arterial prourokinase for acute ischemic stroke: the PROACT II study: a randomized controlled trial: Prolyse in Acute Cerebral Thromboembolism [see comment]. JAMA 1999;282:20032011.

27. Verstraete M. Third-generation thrombolytic drugs. Am J Med 2000;109:52-58.

28. Sakharov DV, Lijnen HR, Rijken DC. Interactions between staphylokinase, plasmin(ogen), and fibrin: staphylokinase discriminates between free plasminogen and plasminogen bound to partially degraded fibrin. J Biol Chem 1996;271:27912-27918.

29. Tanswell P, Modi N, Combs D, et al. Pharmacokinetics and pharmacodynamics of tenecteplase in fibrinolytic therapy of acute myocardial infarction. Clin Pharmacokinet 2002;41:1229-1245.

30. Cannon CP, Gibson CM, McCabe CH, et al. TNK-tissue plasminogen activator compared with front-loaded alteplase in acute myocardial infarction: results of the TIMI 10B trial: Thrombolysis in Myocardial Infarction (TIMI) 10B Investigators. Circulation 1998;98:2805-2814.

31. Torr SR, Nachowiak DA, Fujii S, Sobel BE. "Plasminogen steal” and clot lysis. J Am Coll Cardiol 1992;19:1085-1090.

32. Haley EC Jr, et al. A pilot dose-escalation safety study of tenecteplase in acute ischemic stroke. Stroke 2005;36: 607-612.

33. Parsons MW, et al. Acute ischemic stroke: imaging-guided tenecteplase treatment in an extended time window. Neurology 2009;72:915-921.

34. Haley EC Jr, et al. Phase IIB/III trial of tenecteplase in acute ischemic stroke: results of a prematurely terminated randomized clinical trial. Stroke 2010;41:707-711.

35. Qureshi AI, Ali Z, Suri MF, et al. Intra-arterial thirdgeneration recombinant tissue plasminogen activator (reteplase) for acute ischemic stroke. Neurosurgery 2001;49: 41-48; discussion 48-50.

36. Schleuning WD. Vampire bat plasminogen activator DSPAalpha-1 (desmoteplase): a thrombolytic drug optimized by natural selection. Haemostasis 2001;31:118-122.

37. Liberatore GT, Samson A, Bladin C, Schleuning WD, Medcalf RL. Vampire bat salivary plasminogen activator (desmoteplase): a unique fibrinolytic enzyme that does not promote neurodegeneration. Stroke 2003;34:537-543.

38. Hacke W, Albers G, Al-Rawi Y, et al. The Desmoteplase in Acute Ischemic Stroke Trial (DIAS): a phase II MRI-based 9-hour window acute stroke thrombolysis trial with intravenous desmoteplase. Stroke 2004;36:1241-1246.

39. DIAS-2 Investigators. Intravenous desmoteplase in patients with acute ischaemic stroke selected by MRI perfusion-diffusion weighted imaging or perfusion CT (DIAS-2): a prospective, randomised, double-blind, placebo-controlled study. Lancet Neurol 2009;8:141-150.

40. Albers GW, von Kummer R, on behalf of the DIAS-3 and DIAS-4 Study Group. Desmoteplase 3-9 hours after acute ischaemic stroke: an update on the DIAS clinical trial program. Presented at the International Stroke Conference 2010. Release no. 395. Available at: http://hugin.info/ 130085/R/1388501/346737.pdf.

41. Sherman DG. Ancrod. Curr Med Res Opin 2002;18(suppl 2):s48-s52.
42. Reid HA, Chan KE, Thean PC. Prolonged coagulation defect (defibrination syndrome) in Malayan viper bite. Lancet 1963;1:621-626.

43. Bell WR, Pitney WR, Goodwin JF. Therapeutic defibrination in the treatment of thrombotic disease. Lancet 1968; $1: 490-493$.

44. Sherman DG, Atkinson RP, Chippendale T, et al. Intravenous ancrod for treatment of acute ischemic stroke: the STAT study: a randomized controlled trial: Stroke Treatment with Ancrod Trial. JAMA 2000;283:2395-2403.

45. Ehrly AM. Influence of arwin on the flow properties of blood. Biorheology 1973;10:453-456.

46. Pollak VE, Glas-Greenwalt P, Olinger CP, Wadhwa NK, Myre SA. Ancrod causes rapid thrombolysis in patients with acute stroke. Am J Med Sci 1990;299:319-325.

47. Olinger CP, Brott TG, Barsan WG, et al. Use of ancrod in acute or progressing ischemic cerebral infarction. Ann Emerg Med 1988;17:1208-1209.

48. Hossmann V, Heiss WD, Bewermeyer H, Wiedemann G. Controlled trial of ancrod in ischemic stroke. Arch Neurol 1983;40:803-808.

49. Levy DE, del Zoppo GJ, Demaerschalk BM. Ancrod in acute ischemic stroke: results of 500 subjects beginning treatment within 6 hours of stroke onset in the Ancrod Stroke Project. Stroke 2009;40:3796-3803.

50. Albers GW, Bates VE, Clark WM, Bell R, Verro P, Hamilton SA. Intravenous tissue-type plasminogen activator for treatment of acute stroke: the Standard Treatment with Alteplase to Reverse Stroke (STARS) study. JAMA 2000; 283:1145-1150.

51. Qureshi AI. Endovascular treatment of cerebrovascular diseases and intracranial neoplasms. Lancet 2004;363:804-813.

52. Qureshi AI, Ringer AJ, Suri MF, Guterman LR, Hopkins LN. Acute interventions for ischemic stroke: present status and future directions. J Endovasc Ther 2000;7:423-428.

53. Qureshi AI, Siddiqui AM, Suri MF, et al. Aggressive mechanical clot disruption and low-dose intra-arterial thirdgeneration thrombolytic agent for ischemic stroke: a prospective study. Neurosurgery 2002;51:1319-1327; discussion 1327-1319.

54. Lewandowski CA, Frankel M, Tomsick TA, et al. Combined intravenous and intra-arterial $r$-TPA versus intraarterial therapy of acute ischemic stroke: Emergency Management of Stroke (EMS) bridging trial. Stroke 1999; 30:2598-2605.

55. Keris V, Rudnicka S, Vorona V, Enina G, Tilgale B, Fricbergs J. Combined intraarterial/intravenous thrombolysis for acute ischemic stroke. AJNR Am J Neuroradiol 2001; 22:352-358.

56. Boulos AS, Levy EI, Bendok BR, et al. Evolution of neuroendovascular intervention: a review of advancement in device technology. Neurosurgery 2004;54:438-452; discussion 452-433.

57. Abciximab in acute ischemic stroke: a randomized, double-blind, placebo-controlled, dose-escalation study: the Abciximab in Ischemic Stroke Investigators. Stroke 2000;31:601-609.

58. Adams H. AbESTT II. A Study of effectiveness and safety of abciximab in patients with acute ischemic stroke. Stroke 2008:39:87-99.

59. Lee M, Hong KS, Saver JL. Efficacy of intra-arterial fibrinolysis for acute ischemic stroke: meta-analysis of randomized controlled trials. Stroke 2010;41:932-937. 


\section{Neurology}

\section{Advances in thrombolytics for treatment of acute ischemic stroke Jawad F. Kirmani, Ammar Alkawi, Spozhmy Panezai, et al. Neurology 2012;79;S119-S125 \\ DOI 10.1212/WNL.0b013e3182695882}

This information is current as of September 24, 2012

\section{Updated Information \& Services}

References

Subspecialty Collections

Permissions \& Licensing

Reprints including high resolution figures, can be found at: http://n.neurology.org/content/79/13_Supplement_1/S119.full

This article cites 56 articles, 17 of which you can access for free at: http://n.neurology.org/content/79/13_Supplement_1/S119.full\#ref-list1

This article, along with others on similar topics, appears in the following collection(s):

\section{All Cerebrovascular disease/Stroke}

http://n.neurology.org/cgi/collection/all_cerebrovascular_disease_strok e

Information about reproducing this article in parts (figures,tables) or in its entirety can be found online at:

http://www.neurology.org/about/about_the_journal\#permissions

Information about ordering reprints can be found online:

http://n.neurology.org/subscribers/advertise

Neurology ${ }^{\circledR}$ is the official journal of the American Academy of Neurology. Published continuously since 1951, it is now a weekly with 48 issues per year. Copyright Copyright (? 2012 by AAN Enterprises, Inc.. All rights reserved. Print ISSN: 0028-3878. Online ISSN: 1526-632X.

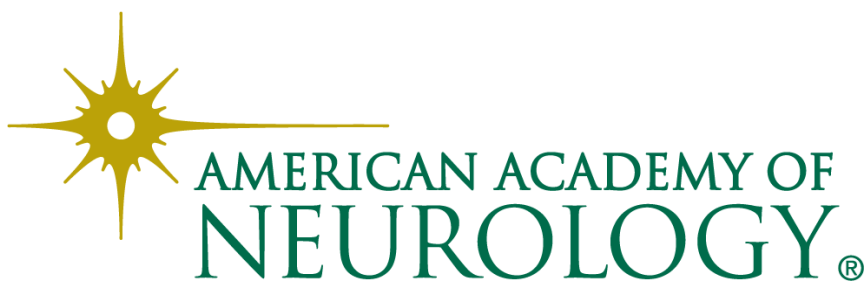

